\title{
VERSOS EN TORNO A JOVELLANOS
}

Fue el profesor Nigel Glendinning, en su artículo «Jovellanos en Bellver y su Respuesta al mensaje de Don Quijote», Mélanges à la mémoire de Jean Serrailh, I (París, 1966), 381, quien primero llamó la atención sobre el hecho de que el ms. 3804 de la Biblioteca Nacional de Madrid contiene poemas de algunos personajes más o menos identificados con D. Gaspar Melchor de Jovellanos. Este manuserito es un tomo de IV + 177 hojas, sin portada, con encuadernación del siglo XIX o del XX, en cuyo lomo se lee POESIAS VARIAS. Es todo de una misma letra, que si no me equivoco, es la de Juan Agustín Ceán Bermúdez; y se hizo a fines de 1805 o algo más tarde, ya que una nota del f. 163 se refiere al Diario de Ma. drid del 7 de septiembre de 1805. Muchos de los textos, sin embargo, son muy anteriores, de los años 1770. Además de los versos publicados o mencionados en las páginas que siguen, el tomo contiene composiciones de Cadalso, Fray Diego González, el P. Juan Fernández de Rojas, Meléndez Valdés, ambos Moratines, Tomás de Iriarte, Francisco Gregorio de Salas, Huerta, Iglesias y "poetas inciertos», amén de la Respuesta que aparece sin indicación de autor, pero que, según ha mostrado Glendinning, es de Jovellanos. Se ve que quien hizo la colección, Ceán u otro, manejaba cantidad de papeles relacionados con la familia de Jovellanos y con muchos de sus amigos.

Creyendo que podría tener algún interés la publicación de algunos de estos versos, le pregunté a nuestro distinguido colega inglés si pensaba editarlos; y en vista de su contestación negativa, los ofrezco aquí. Añado algunos más sacados de otros manuscritos: el 12.929-38 de la Biblioteca Nacional (Epístola de Manuel Santurio García Sala a Jovellanos), el 10.951 de la Biblioteca Nacional (un tomo de Varias poesías procedente de la colección Osuna) y el ms. 355 de la Biblioteca Lázaro Galdiano (Inventario, n. ${ }^{\circ}$ 15.343). En éste, un tomo de Papeles varios del siglo XVIII, se en- 
cuentran sátiras contra la expedición argelina de O’Reilly, el «poema épico» La Sociedad Hispánica de los Enemigos del País y una sátira relacionada con el combate naval de D. Juan de Lángara en el Cabo de San Vicente, que es la que publico.

No quisiera verme obligado a defender los versos que aparecen a continuación como obras maestras del Parnaso español. El interés que tienen se deriva en gran parte de su conexión con la figura de Jovellanos. En algún caso tienen cierto valor biográfico; pero, más que eso, nos dan una idea del clima, tanto poético como ideológico, en que se movía D. Gaspar. Y esto, como no se cansaba de decir D. Antonio Rodríguez-Moñino, es valioso, y tal vez necesario, para comprender bien incluso las figuras cumbres de una época. Efectivamente, los versos de Jovellanos eran contemporáneos no sólo de los de un Meléndez o de un Leandro de Moratín, sino también de los de un Santurio y de los de su propio hermano Francisco de Paula. Quizás los comprendamos algo mejor leyendo también estos otros, ninguno de ellos escrito para la publicación sino sólo para ese comercio intimo de las Musas de que aún gustaban los hombres de fines del siglo XVIII.

J. H. R, PoLT

Universidad de California, Berkeley. 


\section{FRANCISCO GREGORIO DE JOVELLANOS}

D. Francisco Gregorio de Jovellanos, según las Memorias familiares de su hijo ( $B A E$, LXXXVII, 206 y ss.), nació el 18 ó 25 de octubre de 1706. Casó con Francisca Apolinaria de Jove-Ramírez y Fernández de Miranda, hija del primer Marqués de San Esteban del Mar. El cuñado a quien va dirigida nuestra décima debe de haber sido el segundo Marqués, tío de D. Gaspar, D. Alonso Antonio Ramírez de Jove ${ }^{1}$. Según su hijo, D. Francisco Gregorio "era de un corazón franco y generoso, de un entendimiento claro y sublime, y de una virtud ejemplarísima. Se explicaba con la mayor facilidad, de palabra y por escrito; y sin salir de la instrucción que conviene a un caballero de provincia, era lucidísimo en su conversación y la hacía desear de todos por el donaire y agudeza con que se explicaba. Hacía bellísimos versos y tenía tal ingenio para decir de repente, que era siempre la delicia y la admiración de todas las concurrencias». La décima que sigue, únicos versos suyos que conozco, la habrá escrito en el último año de su vida, teniendo ya "sobre setenta y dos», o sea, muy a fines de 1778, o en 1779. Murió el 30 de noviembre de 1779.

Décima de D. Francisco Gregorio Jove Llanos, padre de Jovino, a su cuñado el Marqués de San Esteban con motivo de haberle convidado éste a un banquete.

¿Qué te diré yo, Marqués, cuando estamos ya los dos, yo sobre setenta y dos, y tú sobre ochenta y tres?

5 Sin embargo razón es, haciendo un brindis atento, decirte que yo consiento, según que robusto estás, que todavía vivirás

10 hasta completar los ciento.

(BN Ms. 3804, primeros folios, sin numerar)

(1) Véase Julio SomozA DE Montsontú, Inventario de un jovellanista (Madrid, 1901), p. 247. 


\section{FRANCISCO DE PAULA DE JOVELLANOS}

D. Francisco de Paula de Jovellanos nació el 16 de febrero de 1743, sólo unos once meses antes que su hermano D. Gaspar. Según dos relatos de éste en sus Memorias familiares, ya citadas, en 1760 fue recibido en la Compañía de Reales Guardias Marinas en Cádiz, y posteriormente navegó a América, de donde volvió como teniente de fragata en 1773. Otra vez se embarcó; "y permaneciendo en Montevideo durante la pequeña guerra que hubo con los portugueses, al fin de ella fue nombrado para tirar la línea divisoria de nuestros dominios con los [de] aquellos vecinos sobre la orilla del Río Grande. La duración de esta honrosa comisión era muy gravosa al D. Francisco, que estaba casado por poderes desde $177 \ldots$, por lo que pidió y obtuvo que se le exonerase de ella; y libre de este cuidado se embarcó en el paquebot Tucumán para volver a España». «Pero arribando a la costa de Galicia cuando los ingleses, antes de declarar la guerra de aquel año, habían empezado ya las hostilidades contra nosotros, se halló de repente atacado por un corsario de aquella nación». Gracias a la presencia de ánimo y dotes militares de D. Francisco, el Tucumán, casi desprovisto de armamento, se salvó con toda la correspondencia y otros efectos que llevaba. Como recompensa D. Francisco fue ascendido a capitán de fragata y nombrado teniente de la compañía de Guardias Marinas de El Ferrol; y también obtuvo una licencia para ratificar su matrimonio. Parece que éste, que se trataba desde 1774, no era muy del gusto del novio, pero que se había plegado a los deseos de su padre, como mayorazgo que había llegado a ser por la muerte de hermanos mayores. La novia fue $\mathrm{D}$. $^{\mathrm{a}} \mathrm{Ma}$ ría Gertrudis del Busto y Miranda, mayorazga de la villa de Pravia. Todo este episodio naval, ocurrido en 1778 o $1779^{2}$ y narrado por su protagonista con ejemplar modestia, forma el asunto de la primera epístola que publico.

Durante la residencia forzosa de D. Gaspar en Gijón entre 1790 y 1797 , los dos hermanos, según el testimonio de los Diarios del menor, convivieron en la más entrañable amistad y amor; y D. Francisco de Paula colaboró

(2) En la primera de sus Memorias familiares, que Somoza (Documentos para escribir la biografia de Jovellanos [Madrid, 1911], I, 39) fecha en 1784, D. Gaspar da 1778 como el año de la vuelta de su hermano (v. $B A E$, LXXXVII, 211). En la segunda, escrita en 1810, dice que el viaje se efectuó en 1779 (ibid., 218), en junio de cuyo año se declaró la guerra a los ingleses. Si bien esta última circunstancia hace más probable la fecha de 1779 , también es verdad que este año sólo lo indica el autor más de treinta años después de los sucesos. 
en la gran obra de D. Gaspar, el Real Instituto Asturiano. Su muerte, ocurrida el 4 de agosto de 1798 (Somoza, p. 255), amargó aún más la triste situación de D. Gaspar cuando volvió a Gijón después de ser destituido como Ministro de Gracia y Justicia. "Era este buen hermano de un talento clarísimo, muy instruido en las humanidades latinas y castellanas, y buen matemático. Hacía muy buenos versos...) ( $B A E$, LXXXVII, 219-220). De la opinión que a D. Gaspar le merecían las dotes poéticas de su hermano da fe el hecho de haberle enviado, con una carta importante, sus propios Entretenimientos juveniles ${ }^{3}$.

El soneto que publico a continuación debe de ser de fines de 1778 o principios de 1779, ya que se refiere a una (epístola heroica», que es la III de D. Gaspar, a sus amigos de Sevilla, comenzada y tal vez acabada en octubre del 78. Parece lógico suponer que D. Gaspar enviara una copia de la epístola a su hermano poco después de compuesta. La Epistola al Marqués*** se escribió, como lo indican sus versos finales, en seguida después de la vuelta a España de D. Francisco de Paula. No sé quién fue el destinatario; pero parece haber compartido las aficiones humanísticas del marino y no haber residido en Asturias, adonde éste se ponía en viaje. La Epístola a su hermano Jovino es un poco más difícil de fechar. Creo que se compuso en América al volver allí, repentina e inesperadadamente, su autor, quizás con la expedición de Ceballos en 1776. Así se explicarían el "otro clima y otro cielo» del v. 8 y la (navegación alegre y venturosa» del v. 13, que mal pudiera ser descripción de la referida en la otra epístola. Además, si se hubiese es. crito después de la vuelta a España de D. Francisco de Paula, sería muy sorprendente la ausencia de toda alusión a la aventura pasada y al matrimonio. Por lo tanto creo que los versos 65.67 han de tomarse en un sentido futuro. En todo caso, la epístola se escribió viviendo el padre del autor (v. 31) y antes de la traición de Enarda, amada de D. Gaspar, en el verano de 1779 (vv. 9-11).

\section{SONETO A SU HERMANO}

Es verdad que te enseño a escribir breve, y por eso, Gaspar, admito el cargo,

(3) Véase Jovellanos, Poesias, ed. José Caso González (Oviedo, 1961), págs. 62, 89 y ss. 
pues aunque tu retorno me sea amargo, penitencia también será no leve.

5 Pero mi amor de nuevo inculcar debe, ofreciendo en su abono otro descargo, que si en mis cartas yo no escribo largo, jamás mi amor a no escribir se atreve.

Pero ya te disculpa mi ternura,

10 ya todo enojo el corazón aparta; estímamelo poco, que es usura, pues si me falta alguna vez tu carta. una epístola heroica ${ }^{4}$ y su lectura bien del corto silencio se descarta.

(BN Ms. 3804, f. 1)

\section{EPISTOLA AL MARQUES}

Ni yo de ti, Marqués, menos espero que me has de traducir la cuarta elegia de los Tristes de Ovidio en el Tercero ${ }^{5}$.

Testimonio darás que el aura regia

5 inconstante derroca, precipita, y jamás suerte alguna privilegia ${ }^{6}$

Verás cómo mi musa se desquita de esta fineza que a la tuya encarga, a la tuya, que sé que es exquisita.

$10 \mathrm{Y}$ no te sea mi petición amarga, pues la buena amistad que nos debemos hace leve la más pesada carga.

Ya yo pongo las manos en los remos; métete tú, Marqués, también en boga,

$15 \mathrm{y}$ al numen de las Musas invoquemos.

Pidelo el ritmo; la quebrada soga añudaré pa que [sic] seguidamente sepas mi historia: empeño que me ahoga.

(4) V. Jovellanos, Poesías, ed. Cago, págs. 148 y 88.

(5) Es decir, la cuarta elegía del tercer libro.

(6) La rima de los versos 2,4 y 6 «brilla por su ausencia». 
Después que el Tucumán salvó su gente

20 en el vil surgidero de Malpica ${ }^{7}$

a pesar del corsario diligente,

el capitán a los de tierra explica

el interés de carga y de caudales

y la gran sed que de ello al inglés pica.

Suenan encarcelados los metales

en indigna prisión de vil madera;

si así siempre, ¡dichosos los mortales!

Desde el buque a las lanchas salen fuera

y de las lanchas a la playa, al puerto,

30 ni paran en la playa tan siquiera.

Logrado ya tan importante asunto

y asegurada la correspondencia,

se trató entonces de otro grave punto.

Los prácticos del puerto, en la experiencia

35 de la arriesgada costa bien fundados, aconsejan dejar la residencia;

pues si acaso los vientos, enojados

de soplar tantos días del poniente,

se trasladan del norte a los estados,

40 el riesgo de un naufragio es inminente,

con la infalible infausta circunstancia

de allí morir la miserable gente.

$\mathrm{Y}$ así con acertada vigilancia

zarpamos antes de la aurora fría:

45 forzosa aunque arriesgada circunstancia.

Su lento rumbo el Tucumán seguía

entre la costa y bajos de Baldayo ${ }^{8}$,

o entre Escila y Caribdis, aquel día.

Asomaba del sol el primer rayo

50 cuando a su luz nos libertó Neptuno

del mar y del inglés todo el desmayo.

Ya la torre de aquel a quien ninguno supo igualar en fuerzas se divisa, de Hércules, que también vivió Porcuno ${ }^{9}$.

55 A su vista del gozo el alma risa

(7) Puerto de la provincia de La Coruña, poco seguro.

(8) Arenal de la provincia de La Coruña, cerca de Malpica. 
se pinta en cada náutico semblante,

del puerto amado por feliz premisa.

¡Oh, qué valientes en aquel instante, que ni se vía ni temía el corsario,

60 eran los mismos que con él delante...

Pero siga la pluma aire contrario. Fondeamos felizmente en La Coruña, venciendo de Neptuno el hado vario ${ }^{10}$.

Aun no del ancla la esquinada uña

65 del deseado fondo se había asido (cetro que en paz el dios del mar empuña),

cuando del puerto a bordo habían venido mil gentes, o por fuerza de su empleo, o de curiosidad por la cupido ".

70 Ya los gritos escucho de Himeneo, que su antorcha me enseña desde Pravia, ya la heroína de Montaña veo.

Adiós, Marqués, que la amorosa rabia y el amor de la patria me estimula

75 a huir de toda quilla y toda gavia.

Lo dicho, dicho; y al cancel la mula.

A Asturias marcho si la real licencia para el ansiado viaje no lo anula.

Llegó, a Dios gracias, con que en consecuencia

80 el resto de esta relación prolija irá en otra ocasión. Marqués, paciencia; no cabe todo en sola una valija.

(BN Ms. 3804, f. 2)

\section{EPISTOLA A SU HERMANO JOVINO}

También yo con razón de la fortuna puedo quejarme, porque a mis deseos

(9) La Torre de Hércules es el faro de La Coruña; pero no sé por qué Hércules «también vivió Porcuno», a menos que esto sea una alusión al cuarto de sus trabajos, la caza del jabalí de Erimantea.

(10) Ms.: vano.

(11) 'O por el deseo de la curiosidad', 'por mor de la curiosidad'. 
se opuso esquiva, trastornando instancias que en irte a ver buscaban su consuelo.

5 Huyeron de estrecharte entre mis brazos las dulces esperanzas, por los vientos que a una con la suerte a otro destino me traen, a otro clima y otro cielo que un mísero pais cubre; entre tanto

10 privilegiada víctima tu afecto de un bello numen, sobre inmensos votos logran los tuyos deseado puerto.

Navegación alegre y venturosa tuve. Con humildad desde hoy respeto

15 al estampar mi planta blanda arena, al gran gobernador del elemento, que escuchando tus votos por mi vida, la libertó del mar, peligro extremo. Si mi partida tanto te ha costado

20 de cuidados, de súplicas, de ruegos, aun teniendo tan próximo el alivio de un ídolo benigno, por lo menos, ¿cuál será mi dolor con la noticia de mi forzoso arranque a extraño cielo?

$25 Y$ mientras en ése no podrá estorbarte nadie tu amor, a mí el destino fiero las olas me ofreció por dulce alivio, negándole a mis ojos dulce objeto ${ }^{12}$. ¡Feliz yo, y más feliz, si descansado

30 de náuticas fatigas en su seno nos miraran a un tiempo nuestros padres! Entonces mi placer con tu contento se arrullarian recíprocos; y como alegre por la playa el marinero

35 se goza en recoger de su naufragio para eterna memoria tristes restos, así los dos, colmados de alegría, pisando con placer el patrio suelo,

(12) No es raro el empleo de le como plural. Hay varios ejemplos en las poesías de Meléndez Valdés. Para el uso de le con antecedente plural vid. Lazarillo de Tormes, ed. José Caso González, (Madrid, 1967), 126, n. 185. 
cogeremos en los paternos lares.

40 dulces frutos de afanes y tormentos.

Agradable recreo desde entonces

adulará tu oido por los vientos

cuando percibas el confuso ruido

que al umbral del togado con funesto

45. y triste son de míseras faenas

levante el vulgo, intolerable estruendo;

a menos que de amor con dulce arrullo

las cándidas palomas el recuerdo

den a tu corazón que del reposo

50 sea capaz de privarte: si el sereno

rostro halagüieño del ídolo ${ }^{13}$ tuyo

fiel repasa tu mente, ya el consuelo

que pudieran causarte patria y padres

no será para ti tan dulce y tierno,

55 pues sabe amor hacer destino ingrato

todo el en que no esté el amado objeto,

como en el Ponto suspiraba triste

el gran poeta, de su vuelta incierto.

En fin, del cielo nunca irá distante

60 mi súplica por que tus años tiernos

salven tu honor del vulgo vil y triste;

a tus méritos dando nombre eterno,

premie recompensando tus afanes

con bendecir tus múltiplos [sic] talentos.

$65 \mathrm{Y}$ en tanto que obediente me resigno,

si bien gustoso no, al paterno ruego,

abandonando a Marte, de tus votos

te pido sea mi bien perenne empleo,

hasta que breve límite a tu ausencia

70 ofrezca al corazón sumo contento.

(BN Ms. 3804, f. 6)

Otro hermano de D. Gaspar, D. Gregorio de Jovellanos, nacido en 1746, tuvo la mala suerte de acabar como asunto de versos burlescos, gracias a su

(13) En el ms., idólo, forma que mejora el verso, pero que no registra el diccionario. 
papel en la batalla naval del Cabo de San Vicente. Allí el distinguido marino D. Juan de Lángara y Huarte, al mando de nueve navios y dos fragatas, divisó el 16 de enero de 1780 una escuadra inglesa de veintiún buques, mandada por el Almirante Rodney. Temiendo verse envuelto por el enemigo, Lángara dio la orden de volver al puerto; pero a pesar de esta orden, sólo se salvaron las fragatas y cuatro de los navíos, volándose uno y teniendo que rendirse los demás, con muchos heridos, entre ellos el propio Lángara. Esta derrota «deshizo en una sola tarde lo que bloqueando a $\mathrm{Gi}$ braltar se había adelantado en seis meses», dice Ferrer del Río ${ }^{14}$; y añade: «No juzgando por el éxito, a la manera de los espíritus vulgares, Carlos III galardonó magnánimamente la bizarría de los vencidos», ascendiendo a teniente general a Lángara y ascendiendo igualmente a otros oficiales. Sin embargo, parece que hubo bastantes "espíritus vulgares» que no comprendían bien el por qué de estos ascensos y que desahogaron sus sentimientos en composiciones satíricas conservadas en varios manuscritos, como el 10.951 de la Biblioteca Nacional, donde se lee esta décima al asunto (f. 136):

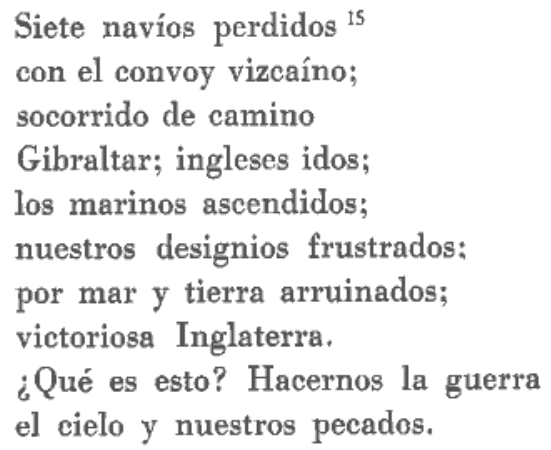

No es más caritativa la siguiente redondilla con motivo del ascenso de Lángara, tomada del mismo manuscrito:

Por perder siete navíos

a uno hicieron general.

Al que pierda veinte y cinco, pregunto yo, ¿qué lo harán?

(14) Antonio Ferrer del Río, Historia del reinado de Carlos III en España (Madrid, 1856), III, 299. El relato que hago es resumen de lo dicho por Ferrer del Río en las págs. 294-300.

(15) Lángara no parece haber perdido más que cinco. 
A continuación viene un epitafio burlesco del hermano de D. Gaspar; pero como su texto se da con mayor corrección en el ms. 355 de la Biblioteca Lázaro Galdiano ( $\sin$ foliar), lo copio de allí con la introducción que le precede:

En el desgraciado combate que tuvo D. Juan de Lángara en los Cabos de S. Vicente con el Almirante Rodney, que venía al socorro de Gibraltar, sólo tuvo la desgracia de morir Jove-Llano [sic] de entre los oficiales de marina, de resulta de las heridas que recibió. Como no acabó en el mismo acto, y sí después de haberles dado los ingleses libertad bajo su palabra de honor, tuvo el consuelo de expirar en el Campo de Gibraltar, y habiéndose esparcido alli inmediatamente un epitafio, que es como se sigue:
Aquí yace Jovellano,
único en su triste suerte
de ser herido de muerte ${ }^{16}$
en el combate britano ${ }^{17}$.
En esta caja ${ }^{18}$ se encierra
con gusto ${ }^{19}$, pues por no hablar
de lo que pasó en la mar,
se metió ${ }^{20}$ bajo la tierra.

Murió D. Gregorio el 10 de febrero de 1780 (Somoza, 255). Su hermano sólo dice de él que "ya falleció» (BAE, LXXXVII, 208).

\section{MARIANO COLON DE LARREATEGUI}

D. Mariano Colón de Larreátegui nos es conocido como colega de Jovellanos en la Sala de Alcaldes de Casa y Corte a partir de 1778 y como el Anfriso a quien Jovino (o, en los impresos anteriores a 1960, Fabio) dirige su célebre Epistola escrita desde El Paular ${ }^{21}$. De este poema publicó José

(16) Ms. 10.951: el que fue

(17) Ms. 10.951: británico

(18) Ms. 10.951: tumba

(19) Ms, 10.951: gustoso

(20) Ms. 10.951: mete

(21) Esta identificación la confirma Juan Agustín Cbán Bermúdez, Memorias para La vida de Excmo. Sr. D. Gaspar Melchor de Jove Llanos, y noticias analíticas de sus obras, Madrid, 1814, p. 295. 
Caso González en 1960 una primera versión (BBMP, XXXVI, 109 y ss), reimpresa poco después en su edición crítica de las Poesías de Jovellanos. D. Gaspar llama a su amigo (favorito / de Apolo y de las Musas» (vv. 7-8 de la primera versión) y se refiere a su «cantar sabroso» (v. 9, idem), que en la segunda versión promueve a (celeste canto» (v. 9). Sin embargo, no se sabía nada de las producciones poéticas de Colón hasta que Nigel GIendinning anunció el hallazgo de sus versos en el ms. 3804. Los poemas que allí aparecen son los tres que publico ahora. Atención especial merece la Egloga, fruto de la misma situación vital que produjo una de las obras maestras de Jovellanos, su Epístola IV, la escrita desde El Paular, en su versión primitiva. Confirma cuanto allí nos dice Jovellanos sobre el origen amoroso de sus males, y nos añade algunos, aunque pocos, pormenores sobre las relaciones entre Jovino y «la infiel Enarda», sin identificar a ninguno de los personajes ${ }^{22}$. El gusto por la máquina mitológica (vv. 37 y ss.), de antecedentes clásicos, lo comparte Colón con su amigo, quien ya había dado muestra de él en su Epístola I, Carta de Jovino a sus amigos salmantinos (ed. Caso, pp. 120 y ss.), donde (la Invidia» conspira contra la fama de los poetas amigos.

Los tres poemas de Afriso pueden fecharse con bastante exactitud. Siendo la Epístola IV de Jovellanos de julio de 1779 (Caso, p. 175), es lógico suponer que la respuesta de Colón, su égloga, sea muy poco posterior a ella. En cambio, la Canción de Anfriso, que habla todavía de «la fiel Enarda) (v. 3), debe de ser anterior a julio del 79, pero posterior a octubre de 1778, cuando parece que se conocieron los dos amigos (Caso, p. 173). En cuanto al soneto que el manuscrito fecha 1779 , ha de ser de diciembre de aquel año, ya que el padre de Jovellanos murió el 30 de noviembre. En el ms. 3804 consta sólo el seudónimo del autor, Anfriso, no su nombre o apellidos.

\section{CANCION DE ANFRISO}

Amado Fabio ${ }^{23}$, que [con] voz sonora cantas por dulce triunfo tus afectos,

(22) Véase Caso, ed. cit., p. 21 para las relaciones anteriores entre Jovellanos y Enarda, cuyo nombre verdadero se ignora.

(23) El empleo de este seudónimo muestra que su presencia en la Epístola IV de Jovellanos no se debe sólo al capricho. 
correspondidos de la fiel Enarda, envidiados de muchos mal contentos:

5 oye la voz de tu pastor Anfriso, que te escribió venturas otro tiempo desde los campos que Jarama y Tajo fecundan y sazonan con su riego. Oyelo ahora de su ingrata Lisi ${ }^{24}$

10 ultrajado con viles menosprecios, y verás un resumen de sus quejas y de sus desgraciados sentimientos. Oyelo, que no siendo concebido de hircana tigre o de león sangriento

15 tú te condolerás del triste estado de tu amigo leal y compañero.

El otro día, cuando el sol oculto se iba después del ${ }^{25}$ alba descubriendo, así en tristes cadencias entonaba

20 a la margen de un plácido arroyuelo:

«Pastores muy amados que el rebaño guardáis conmigo en este alegre suelo, no me lengáis envidia porque rico de campos y ganados me estáis viendo,

25 ni porque de vigor y alguna gracia me dotó afable por ventura el cielo. Estas dichas, si así pueden llamarse, vienen para mí a ser de ningún precio.

¿De qué aprovechan dichas si tú, ¡oh Lisi!

30 faltaste a nuestro amor, amor primero? ;Amor con que me abraso en vivas ansias y que me sirve de fatal tormento!, por el cual yo no soy el que solía, ni ya pienso vivir, sino en desprecio.

35 Viviré desgraciado y abatido, de mi mismo olvidado, y seré luego enemigo cruel de mi descanso,

(24) No sé quién fue Lisi, que aparece también como amada de Anfriso en poemas de Jovellanos. V. ed. de Caso, p. 179, y también las págs. 173-174, donde aparece como Lisa.

(25) Ms.: después al. 
y quien a sí ${ }^{26}$ se vaya aborreciendo.

Ah Lisi, que cruel conmigo, ingrata,

40 eres causa de males tan funestos, ¿por qué siquiera por piedad no curas mi corazón herido y casi muerto?

Dime si me amas. Di si te enternecen o acaso te fastidian ya mis ruegos.

45 Pero, ¿qué estoy hablando? Ya te enfadan y aun los miras con odio el más protervo. ¿No te mueven, infiel, mis tristes ayes, ni mi Ilanto, continuo como tierno? Llanto a quien seguirá después la muerte,

50 dulce y tranquila en males tan horrendos. Si [tú] dices [que] me amas, cruel Lisi ${ }^{27}$, me engañas, porque en otros tienes puesto algún cuidado, que si no cariño, es a lo menos estudiado aprecio.

55 No envidio esos felices; mas te pido dejes de atormentar mi amante pecho con liviana esperanza o con lisonja para mayor dolor, mayor tormento; que cuando por acaso me encontrares

60 huyas de mi, que con semblante fiero me mires, y ejercites con Anfriso los odios más atroces y severos. Acaso de este modo, ingrata Lisi, moriré de una vez, verdugo siendo

65 tu misma crueldad, porque se acabe el pasado rigor de fin tan lento. $\mathrm{Y}$ si tú quieres te anticipe el gusto de mi sepulcro y de mi amor postrero, mira ese río pronto a recibirme

70 y me será mi tumba y monumento. Allí también hay rocas escarpadas de donde en precipicio ${ }^{28}$ el más violento

(26) Ms.: asi.

(27) Suplo dos palabras que no cambian el sentido del verso y sin las cuales éste queda muy defectuoso.

(28) Ms.: pricipio. 
bajaré al valle, si antes no me acaba mi desesperación y mi despecho.

75 Pero tú mirarás esta tragedia con semblante pacífico y sereno, y acaso burlarás con mis rivales mis funerales y mi fin tremendo.

Dirás entonces: 'Este por mi muere',

80 y harás ostentación de tu trofeo; al pasajero mandarás que pise mis cenizas con burla y con desprecio.

Vosotras, mudas selvas, y vosotras, tiernas ovejas, a quien yo defiendo

85 de la lluvia y el sol, seréis sin duda más piadosas conmigo que mi dueño. Segu[i]réis mi cadáver compasivas, y con tristes balidos en mi entierro de Lisi culparéis la injusta ira,

90 y diréis murmullando entre lamentos: 'Este es el fiel pastor que amando a Lisi murió de amor, y en su fallecimiento ni una lágrima sola ha merecido a la cruel, de su fineza en premio'.

95 Vientos, testigos fieles de mi llanto, también de mis suspiros los más tiernos, si alguno me encontrare entre la arena ser desperdicio vil de aves y perros, decidle: Aprendan todos los que aman 100 si el amar es al fin ${ }^{29}$ de algún provecho. Anfriso amó, y la muerte más horrible de su fatal amor ha sido efecto's.

(BN Ms. 3804, f. 127)

(29) Ms.: el fin. 
A las riberas del estéril río que los mantuanos ${ }^{30}$ campos humedece estaba Anfriso publicando dichas al son de las zampoñas y rabeles.

5 Allí el ganado alegre retozaba, y Anfriso le cuidaba muchas veces, y en compañía de su amable Lisi otras mil paseaba el prado verde. Jovino, otro pastor, que aun en los campos

10 las sazonadas musas entretiene, le visitaba, y con la dulce flauta sus elegantes versos entreteje. Era de oír cómo sonando en ecos de Enarda el nombre por los aires hiere, $15 \mathrm{y}$ cómo Anfriso de su ingrata Lisi himnos entonna y el aplauso crece. Cual céfiro bullendo entre las ramas, cual cristal que en las guijas se divierte, así los nombres de las dos pastoras

20 se escuchan por los campos dulcemente. Viva Lisi se lee en aquel olmo; gracias de Enarda el otro tronco ofrece; y en aquél de mil rústicos dibujos tiernas de amor alegorías penden.

25 Así los cuatro, en tiempo que el descanso de sabrosa quietud caudal ofrece, templaban los rigores del invierno y las fatigas del estío ardiente. Ellos gozaban juntos los festines, 30 los rústicos festines, do se suele encender el amor más apagado y arder el fuego aun en pavesas leves. Gustaban con unión los regalados

(30) Madrileños. 
y los puros y cándidos placeres,

35 ya en el tierno cordero, ya en la nata, y ya en la fresca y espumosa leche.

Así vivían, cuando infernal furia cubre el aire de densas fetideces:

la envidia, en fin, ese horroroso monstruo,

40 en los mantuanos campos aparece.

Busca a Celeno, una implacable harpía, y así la habla con adusta frente:

"Oh tú, furia cruel, que a los troyanos aterraste, y sus bien armadas huestes ${ }^{31}$;

45 tú que, mi compañera inseparable, jamás felicidad ni unión consientes: mira a Enarda y Jovino, Anfriso y Lisi, que los cuatro mortales no parecen. Ellos, gustando de una quieta vida,

50 ni los disgustos ni los celos sienten. ¿Y tú consentirás que tanta dicha con amargo pesar hoy no se mezcle?»

Dijo; y la fiera harpía con sus alas del aire la región así estremece,

55 cual furioso huracán, cual terremoto, con silbos, con bramidos, con vaivenes.

Llega a Mantua y empieza con Anfriso

a ejercitar sus tiros más crueles, y en el pecho de Lisi clava un dardo

60 con veneno de olvidos y desdenes.

Celeno, cruel monstruo, no se sacia.

y el amor de Sapino aleve enciende ${ }^{32}$;

y disfrazada en traje de pastora

el encendido amor asi promueve:

65 Labra una choza que, vecina a Lisi, era del nuevo amor traidor albergue, y e[n] ella con Sapino y Lisi trata contra Anfriso los pactos más infieles.

(31) V. Eneida, III, 216 y ss.

(32) Ms.: y el amo de Sapino alave enciende. No sé quién puede haber sido Sapino, cuyo nombre parece derivado de sapo, ni quién fue el rival de Jovino, Coridón, mencionado en el v. 95. 
¡Oh tú, madre de Amor! ¡oh tú, alma Venus! tus altares las furias? Pero acaso porque más altas caigan las consientes.

Ya Lisi no se acuerda de su Anfriso; y lo que es más, ya Lisi le aborrece, 75 y al lado de Sapino día y noche Ia furia sus sentidos adormece. Es Sapino un pastor disforme y tosco, torpe en su explicación. Lisi le excede cuanto suele... Mas callo, pues me abraso

80 cuanto ella más hermosa me parece.

$\mathrm{Y}$ vamos a que el monstruo, no contento con romper de mi amor los nudos fuertes, a Enarda, en fin, a la inocente Enarda, emponzoña también, y al amor vence.

85 Jamás Enarda de traición o agravio se creyó ser capaz. Dócil previene las leyes que Jovino le prescribe, y ni por sombra a su Jovino ofende. Mas, ;ay!, también la furia, contagiando

90 del olvido de Lisi a la inocente, hace con el ejemplo más estrago que sus furias de Troya en los manteles ${ }^{33}$. $\mathrm{Y}$ viendo que de Enarda la constancia es superior, dispone que se ausente,

95 y siga Coridón sus bellos pasos, suavizando nativas esquiveces.

Ya ni escribe a Jovino, ya le olvida; y tampoco le busca cuando vuelve. ¡Ah!, cómo la soberbia y el orgullo

100 con el amor constante no convienen! ¿Es ésta aquella Enarda, aquella Lisi, que en otro tiempo su pasión sostienen entre tribulaciones y entre riesgos, iguales siempre, en males como en bienes?

105 Las misma[s] son, aunque mudables tanto.

(33) Alusión al ataque repugnante de las harpias durante el banquete que trataban de celebrar los troyanos en las islas Estrófadas (Eneida, III, 225 y ss.). 
¡Cuitados de nosotros! ¡Cómo infieles

de nuestro fino amor han hecho escarnio!

Creímoslas incautos, como suele

el pajarillo en preparado visco

110 caer, y aprisionarse entre las redes.

Permítase que Anfriso con Jovino

temple la lira y su inquietud consuele.

Mas, ¿qué alivio tendrán los dos pastores, sus campos secos, su ganado estéril?

115 Los unos no producen frescas flores;

el otro bala y de pesar se muere.

Desde que Enarda y Lisi se ausentaron,

Apolo y Palas se desaparecen,

y los campos abrojos sólo y cardos

120 llevan en vez de rosas y claveles.

Escarmentemos, pues; que si sacamos

tan útil escarmiento, será éste

de la virtud el triunfo más bizarro,

y nuestro desengaño nuevo fénix ${ }^{34}$.

125 Y tú, pastor divino, que cantaste

del Lozoya a la orilla ${ }^{35}$, no te altere

lo bronco y destemplado de mi plectro,

y al motivo no más benigno atiende;

porque si al estallido que da el bronce

130 el ave herida sus rigores siente,

cuanto el cisne en dulzuras se querella,

el cuervo con graznidos estremece.

(BN Ms. 3804, f. 131)

(34) Estos dos versos parecen titulos de comedias.

(35) En su Epistola, Jovellanos había escrito: «Pártele [al valle] en dos mitades, despeñado / de las vecinas rocas, el Lozoya, / por sus truchas famoso y dulces aguas». (Primera versión, vv, 66-68). 
Si es la gloria del padre un hijo sabio, hoy tu padre eterniza su memoria y a la posteridad deja la gloria de la fama inmortal que da tu Iabio ${ }^{36}$.

No, Jovino, Laqueïs hizo agravio ${ }^{37}$ a un padre si tuvo tal victoria. Tu padre vive, sí. No es transitoria vida a quien dio la parca un desagravio.

«Vivo», dictó al morir, "mi heroica fama en $\mathrm{mi}$ posteridad dejo muriendo, que vale más que vergonzosa vida».

Vive pues, de aquel tronco ilustre rama, y debe tus alivios, sabio siendo, a tu ciencia, no al tiempo, en tal herida.

(BN Ms. 3804, f. 136)

\section{MANUEL SANTURIO GARCIA SALA}

Es poco lo que puedo decir del último de los poetas cuyas obras publico, y este poco sólo es lo que se desprende de sus obras. Su nombre y apellidos constan en el ms. 12.929-38, autógrafo; el ms. 3804 sólo le llama Santurio. En los Diarios de Jovellanos hay referencias a individuos llamados García Sala y a otros con el apellido Santurio; pero no the encontrado ninguna que combine los dos apellidos ni que acompañe uno u otro con el nombre Manuel. Por las dos epistolas se ve que nuestro poeta residía en Madrid, pero que con toda probabilidad era gijonés. Como Meléndez Valdés y Leandro de Moratín, insiste en que Jovellanos ha inspirado sus versoso (I, 8-10 y II, 29-33), hablando del «cuidado paternal» de Jovino y

(36) Ms.: a tu labio. No entiendo esta construcción; no es el padre quien da fama al labio de Jovino, sino que, al contrario, todo el soneto quiere consolar a Jovino mostrándole que su padre vive en él y en sus obras y sabiduría. Tampoco ganaría mucho en claridad la versión del ms. si tomásemos la posterioridad como sujeto de $d a$.

(37) Es decir, Láquesis no hizo agravio. 
llamándole padre, maestro, dueño y protector de su musa. Por lo demás parece haber tenido un conocimiento muy exacto de la vida y obras de D. Gaspar y haber comulgado en las que en su época se consideraban ideas avanzadas. Quizás consista precisamente en el reflejo de las ideas y obras de Jovellanos el mayor interés para nosotros de estas epístolas, testimonios de cómo se consideraba a D. Gaspar en su tiempo. Las dos se escribieron con motivo del cumpleaños y santo de su destinatario. El ms. 3804 conserva otras cuatro poesías de Santurio: dos gratulatorias a Da. M. C. Y. [sic] L. E., una Silva en elogio de la cómica Bermejo, y un soneto a D. J. A. C. B. que felicita a éste en el día de su santo (Juan) y por «la esperanza de nueva prole». EI receptor, sin lugar a dudas, fue otro gijonés muy identificado con Jovellanos y el que, en mi opinión, copió todo el manuscrito 3804: Juan Agustín Ceán Bermúdez. Las fechas de las dos epístolas a Jovellanos constan en los respectivos manuscritos.

EPISTOLA DE SANTURIO A JOVINO

A ti, dulce Jovino, se dirige mi humilde musa, que te lleve ansiosa a los patrios ilustres lares tuyos de mi amistad y gratitud la ofrenda.

5 Recíbela, oh Jovino, y en el seno de la santa virtud le acoge blando y con mano indulgente le acaricia. De tu cuidado paternal es obra; tú la vida le diste con tu aliento,

10 y ora te busca con filial confianza. A ti solo te busca. Tú la senda de la verdad y la justicia sigues, mientras de ella la turba se extravía. ¡Dichosa humanidad, que en tus nat[a]les

15 por siempre sus delicias asegura! Tú naciste, Jovino, y de repente la perfidia y lisonja amedr[e]ntadas de en torno de tu cuna se ah[u]yentaron. Las virtudes sociales acudieron

20 a mecerte festivas. La Justicia a todas precedió. Ella tu alma adornó con sus dones divinales 
para ser de la patria el firme apoyo.

Un pecho te dio entero, a los halagos,

25 al ruego y al favor inexpugnable.

No le ocupa el temor. Las amenazas

no son a perturbarle poderosas.

Tal fue tu educación, tal el esmero

con que en pos de Sofía caminaste.

30 Al fin tus ansias ${ }^{38}$ escuchó; a su templo propicia por la mano te condujo y sus misterios revelarte quiso.

Temis entonces, la sagrada Temis, sus códigos te abrió. Tú te lanzaste

35 por beber su doctrina saludable ${ }^{39}$. Con afán generoso descubriste la linea imperceptible que departe y distingue el derecho que al vasallo y al soberano la razón asigna.

40 Así el velo rasgaste que encubría la existencia del pacto sacrosanto, de este pacto social que al ciudadano sus fueros le asegura. No en el rancio pergamino, del tiempo carcomido,

45 tal pacto apareció, que en la natura del corazón del hombre le encontraste, y claro ante los ojos le pusiste. Por ti vive feliz el que oprimido fuera del poderoso. Por ti dado

50 fue a la orfandad un inviolable asilo. La triste $\vec{v} 1$ uda por tu auxilio pudo su dolor mitigar. ¡Oh, cuánto hiciste en abono del mísero artesano, del labrador y mercadante astuto!

55 Por tu influjo el primero se vio exento de las trabas gremiales que otro tiempo fabricó la ignorancia de consuno

(38) Ms.: ansios.

(39) En los versos que siguen se alude a los estudios y las ideas de Jovellanos y también, al parecer, a determinados escritos suyos, como el Informe sobre el libre ejercicio de las artes, en el cual D. Gaspar combate contra «las trabas gremiales». 
con la falsa piedad. Este fue el monstruo que más a tu placer has combatido.

60 ¿Qué el labrador no debe a tus vigilias, en tus doctos escritos consignadas?

Por ellas libre de opresión trabaja.

Por ellas las naciones más remotas con largueza recogen nuestros frutos,

65 y en cambio mil placeres ignorados a nuestro gusto con esmero of recen. ¿Qué importa que el provecho que se cifra en tu afán desde lejos se presente? Nada perdona tu constancia; nada 70 a tu ingenio se oculta y perspicacia. Así la historia majestuosa corre por la senda segura que señalan el crítico y amante de Sofía. Todo en orden lo tienes concertado;

75 todo a un fijo sistema lo refieres y firme sigues con altiva planta. No la arbitrariedad pudo llevarte a la merced del palaciego. En vano sus armas sprestó, que tus principios

80 del orden general son deducidos, y ellos solos del hombre la conducta, el deber y derecho fijar pueden. Sigue, pues, ¡oh Jovino! tus designios. Síguelos con firmeza generosa.

85 No tu virtud austera el hombre vea en un punto menguar en daño suyo. ¡Oh plegue a Dios que el gijonense suelo, cuyas arenas hoy tu planta pisa. de las remotas gentes sea buscado 90 para admirar el genio que le rige! Entonces selvas de nadantes pinos, que vio el Gange [sic] nacer en sus orillas, robarán a la vista $\mathrm{el}^{40}$ oceano

(40) Ms.: del. 
y oprimirán su espalda humedecida.

95 Entonces, ¡oh gran Gija! ${ }^{41}$, tus murallas

al cielo se alzarán; y tú tranquilo

con suave mano regirás el pueblo

y en suave holganza sonará tu lira.

Madrid, $10^{\circ}$ de enero de 1791.

(BN Ms. 3804, f. 148)

AL EXCMO. SR. D. GASPAR MELCHOR DE JOVE LLANOS EN

CELEBRIDAD DE SUS DIAS,Y EN OCASION DE HABER SIDO

PROMOVIDO AL MINISTERIO UNIVERSAL DE GRACIA Y JUSTICIA

Proferet imperium; jacet extra sidera tellus,
extra anni solisque vias ubi coelifer Atlas
axem humero torquet stellis ardentibus aptum.

Virgilio en su Eneida [VI, 795-797]

¿Qué alborozo, oh Jovino, desde Gades

a Gija hinche la esfera de alabanzas

y aclamaciones mil, tu nombre excelso

de la fama a los ecos entregando?

5 Ya no más vacilar; no más mi musa

tímida continúe y aherrojada

entre masas informes indigestas

de pesados volúmenes que enseñan

del necio interpretar el empirismo.

10 Un momento sacude, oh musa mía,

tus alas vagarosas, que hasta ahora

entre el polvo estuvieron abatidas.

Sacude tu pereza, y por la turba

te mezcla de los genios que hoy con canto

15 sublime solemnizan de Jovino

el triunfo más glorioso, el que más honra

la naturaleza y la razón augusta.

(41) Gijón. 
¿A qué tanto temer? ¿Acaso el ara de Jovino no admite adoradores

20 más que aquéllos que llevan con confianza del sublime saber la rica ofrenda?

¡Ah! con mayor confianza en sus altares perfumes quema gratitud sencilla no de un olor sabeo voluptuoso,

25 sino grato bastante a la piadosa divinidad augusta que se paga de un llano corazón siempre entregado de Verdad y Justicia al sentimiento. Llega, pues, respetuosa; llega al mismo

30 regazo soberano en que naciste, al mismo en que otro tiempo balbuciente a Jovino, tu padre, tu maestro, tu dueño y protector apellidaste. Verás cuál te acaricia. Sí, oh Jovino,

35 de tu alma celestial algún destello en mi musa hallarás. Luego, Jovino, conocerás la musa desvalida que en otro tiempo a provocar se puso en trance desigual al poderoso

40 que, cual el huracán la leve arista, te arrebató en un punto a los Astures, hollando con abierta faz erguida de la amistad los fueros sacrosantos y de verdad austera el simulacro ${ }^{42}$. 45 ;Días aciagos, de vergüenza días, días de proscripciones, de infidencias, de hierro y destrucción! Desparecisteis de la haz de la tierra. La memoria vuestra se disipó. En el abismo

50 de los siglos hundióse, eternamente a obscuridad infame condenada.

Cayó en profunda huesa con el monstruo

(42) No sé si en estos versos ha de verse una alusión a Campomanes, quien hizo un papel poco digno en la caída de Cabarrús y el subsiguiente destierro a Gijón de Jovellanos, amigo de ambos, en 1790. Camponanes se retiró de sus varios e importantes cargos en 1791 . 
que quiso desterrar del suelo patrio

por siempre la virtud, las proscripciones

55 de Sila en nuestro siglo renovando.

Todo pasó en un soplo, y a estos días

sobrevivió tu gloria, oh gran Jovino.

Sobrevive en los ricos minerales ${ }^{43}$

que pusiste al alcance de la ansiosa

60 aplicación del asturiano pueblo,

a la tierra forzando de su seno

las venas arrojar que de hoy más corren

de puntos mil a las vecinas playas,

en donde a recibirlas se apresuran

65 el libro Galo, el Anglo, aunque orgulloso

con el tridente de la mar, el fiero

sueco, dinamarqués, el lusitano,

y hasta el frío y remoto moscovita.

Sobrevive en las vías anchurosas

70 que has abierto a despecho de la intriga,

los pueblos asturianos acercando

a Gija, emporio del comercio, a Gija

nunca vencida y siempre envidiada

porque dio en ti al humanal linaje

75 el Padre de la luz, el que contino

la derrama a los puntos más lejanos,

el que supo fijarla entre sus hijos,

con intrépida mano levantando

de la gloria asturiana el monumento,

80 donde ensanchó de la verdad los senos

que un tiempo fabuloso parecieran.

Sí, vive el Instituto ${ }^{44}$, vive el numen

tutelar que le alzó, vive Jovino.

Su mano divinal doquiera imprime

85 la vida y movimiento. El Instituto

eterno durará porque afianzado

existe so [sic] las basas inmutables

del provecho común, porque en él cifra

(43) Carbón y carreteras eran dos preocupaciones permanentes de Jovellanos, de las cuales dan fe numerosos escritos.

(44) El Real Instituto Asturiano de Náutica y Mineralogía. 
la Nación Española su alta gloria.

90 ¡Ah! ¡cuánto trabajó su autor ilustre contra el manejo monacal que quiso tal obra adulterar y al monopolio de la jerga escolástica lanzarla y a su obscuro lenguaje incomprensible!

95 Apenas sale de tu mano augusta cuando vuela de un pueblo en otro pueblo la vocinglera fama que lo anuncia, hablillas mil a su placer forjando. Provoca a guerra universal. La envidia,

100 la intriga y la ignorancia concitadas corren desde las simas tenebrosas y asaltan por doquiera al Instituto ${ }^{45}$. Empero el Instituto su existencia deriva de un impulso más que humano.

105 Es el Hércules niño que sufoca con imperiosa mano las serpientes que afilando sus lenguas venenosas en torno de su cuna se enroscaban. ¿Quién fuerza le infundió tan poderosa

110 para acabar con enemigos tales? Tanto un dios pudo hacer, tanto se debe a la sabiduría, a la firmeza con que, oh grande Jovino, imperturbable ubservas las discordias que levantan

115 las mezquinas pasiones, bien seguro de poder, cuando quieras, desarmarlas, bien como suele el soberano Jove súbito disipar las tempestades que bajo de sus pies el choque forja

120 de los vientos contrarios procelosos. 'Todo cede al saber, todo a una pura conciencia imperturbable. Todo cede

(45) Los Diarios y el epistolario de Jovellanos nos informan repetidamente sobre la hostilidad que provocó el Instituto en ciertos sectores, sobre todo eclesiásticos. Véanse, por ejemplo, el diario del 5 de septiembre de $1795(B A E, \operatorname{LXXXV}, 322)$ y la carta al obispo de Lugo $(B A E, \mathrm{~L}, 341)$. Sin embargo es justo notar también que eclesiásticos fueron algunos de los benefactores del Instituto. 
a tu ciencia y virtud, oh gran Jovino.

Tú los montes allanas. Tú los ríos

con los ríos ajuntas. Tú los llevas

por desusados lechos. Tú cegados

tornas los pantanosos territorios.

Tú los bosques descuajas. Tú arboledas

alli crías también donde te place.

130 Tú a las ciencias exactas digno asilo

les diste entre los hijos de Pelayo,

en ellas vinculando los progresos

de la navegación tan olvidada.

Formaste un nuevo pueblo de esparciatas,

135 amador del trabajo y de la industria

y de la cara libertad que es hija

de la santa virtud que le enseñaste.

Así venciste a la Opinión. En vano

enemigos rastreros esta gloria

140 de consuno quisieron disputarte.

Superior a ti mismo, a todos ellos

te hiciste superior, y mal su grado

del aplauso te dieron el tributo

a la virtud y al mérito debido.

145 Tanto pudo el gran libro en que se encierra cuanto hay de más certero y más sublime en la Ciencia Económica ${ }^{46}$, que en manos de empíricos librada estuvo un tiempo.

¡Ah! Todo en este libro se dirige

150 a un punto de unidad, y de un principio

las más claras teorías se deducen,

y todas en el mismo se terminan.

No de otra suerte el Hacedor del orbe, poniendo a la materia en movimiento

155 y el placer y el dolor dando a los seres, los dejó desde luego aparejados

a la infinita variedad de formas que la eterna cadena van formando, siempre empero a las leyes primordiales

160 del placer y dolor subordinados.

(46) El Informe en el expédiente de Ley Agraria, publicado en 1795. 
Sola la libertad, solo el gran libro

do existen sus principios consignados

feliz a España podrá hacer un día.

Ya para tal empresa arrebatado

165 fuiste, oh dulce Jovino, al alto asiento

una vez sola por Sofía ocupado.

Sí, Jovino; la Patria deseosa

de tu gobierno está. La Patria clama

por el pronto remedio de sus males.

170 Ve los campos desiertos donde apenas la huella se conoce del arado.

Ve los talleres de las artes todas cuál existen del todo abandonados. Ve los solares yermos que hoy habita

175 una perpetua soledad profunda.

Ve los códigos patrios do se encuentran acá y allá sin orden derramadas ya las leyes que un tiempo gobernaron la ruda y marcial gente visigoda,

180 ya las que en pos vinieron en apoyo del gobierno feudal y sus costumbres, ya las que al pueblo castellano un tiempo libertad dieron y jurados fueros, y ya en fin las que extenso y absoluto

185 hicieron al poder, aunque templado ${ }^{47}$. Ve... Pero no veas los folletos en donde a manos llenas los casuistas todos los extravios compilaron de la humana razón. Envía rayos

190 que a todos en un punto los abrasen. Sólo mande la ley que dimanada de voluntad sea general, y sólo del jurisperito auxiliadores sean el natural derecho, el de las gentes,

195 la Economía elemental, la ciencia

(47) Esta visión de la historia española es bastante característica de los ilustrados. Véase Richard Herr, España y la revolución del siglo XVIII, [Madrid], 1964, págs. 284-289. 
que enseña las costumbres y la historia

nacional que atesore con esmero

lo que al civil estado le interese.

Mas ve, Jovino, la fatal gangrena

200 le superstición y de ignorancia

que a par de las ideas las costumbres

va con rápido paso corrompiendo.

Pronuncia una voz sola, y todo al punto

se verá por tu influjo remediado.

205 Al oír tu elección estremecióse

de dura intolerancia el viejo monstruo.

Un pie puso en el Africa y vacila

si el otro pondrá aun, y aun la Patria

en dura esclavitud yace sumida ${ }^{48}$.

210 Ya de una vez nos deje, y las ciencias ${ }^{49}$

de luz el solio bañaxán de lleno,

de luz las avenidas que conducen

a él desde los ángulos remotos

que fijan aledaños a la tierra.

215 Triunfará la virtud sobre las ruinas

del terror y de vil hipocresía.

A ti esta empresa te reserva el Cielo.

El voto universal te abrió la senda

y por ella gozoso te condujo

220 al grave cargo de regir dos mundos.

Sí, la Justicia triunfadora, ornada

con los despojos de la envidia, acaba

de bendecir las manos que la tornan

al debido esplendor y poderío.

225 El mérito premiar y las virtudes

es el deber primero que a los reyes

el pacto sacrosanto les impone.

Si fieles tales leyes observaren

(48) No me parece muy atrevido ver en este «monstruo» a la Inquisición. Huye al Africa por ser ésta la tierra del Islam, identificado también por Meléndez Valdés con el fanatismo y la intolerancia. Véase su oda $E l$ fanatismo.

(49) Ms.: esciencias, que podría tomarse por esencius o por ciencias. En vista del v. 212 me parece preferible ciencias. 
en tropas mil los pueblos venturosos

230 las palmas alzarán al alto cielo, sus dones soberanos atrayendo sobre aquellos que padres apelliden. ¡Oh cuán bien hoy este deber cumplieron el cuarto Carlos y la amable Luisa!

235 Así su gloria con la tuya unida sonará en el espacio del futuro, jamés reposo en su vagar hallando. ¡Oh, con cuánto placer, oh gran Jovino, oh, con cuánto placer hoy adelanto

240 tal vaticinio a la española gente! Los siglos vuelven de la Grecia sabia y el hado de la Hesperia cumplimiento tendrá en tu suave gobernar, Jovino. El augusto santuario de las leyes

245 de plano se abrirá sólo a quien venga con las dotes divinas adornado de la sabiduría. Avergonzados el vicio y el error de sus umbrales por siempre se huirán. Los monumentos ${ }^{50}$

250 presentes lo aseguran. La Justicia en paz y holganza mantendrá a los pueblos y por la boca de los sabios sólo nos dirá sus oráculos divinos. Acaso alguna vez el fiero Marte,

255 dejando sus guaridas infernales, discordias soplará que más atice la extranjera ambición. Lanzado acaso será por ella a los confines nuestros. No hay temer [sic], pues el Cielo al cuarto Carlos

2 Ło Escipiones dará que le resistan; y mientras los ejércitos, llevando la precisa venganza al enemigo, sus injustos designios desarmaren, vivirá el ciudadano en sus hogares 265 al reposo pacífico entregado.

(50) Monumentos con un sentido semejante al de augurios, que es lo contrario de! que registran los diccionarios. 
El labrador, del suelo recogiendo sobrada mies que su avaricia apague, en ricas trojes guardará encerrados los trigos que después buscará ansioso

270 el mercadante astuto por llevarlos a extranjeras naciones ignoradas, surcando mares en las naves nuestras. Cual el astro del día difundiendo sus rayos bienhechores por doquiera

275 de germinar la fuerza distribuye y lleva la alegría a todas partes, tal el comercio correrá en franquía, ya de estorbos locales desatado. Los útiles canales serpenteando

280 irán por la ancha faz de nuestro suelo y juntando regiones diferentes serán unas por otras abastadas. Digamos de una vez. Desde los techos dorados donde el cetro soberano

285 a los pueblos gobierna, hasta la humilde cabaña en que se abriga la obediencia bajo el sayal virtuoso, oh gran Jovino, sentirá lo acertado de tu mano ${ }^{51}$. Oh, vivas años mil; viva, oh Jovino, 290 por años mil tu gobernar süave para ser de tu Patria la delicia y de todos los hombres el consuelo.

Madrid, 6 de enero de 1798

Manuel de Santurio García Sala

(BN Ms. 12.929-38)

(51) Es decir, todo «desde los dorados techos hasta la humilde cabaña sentirám. 